\title{
Phase Current Reconstruction Techniques for Two-Phase Inverters using a Single Current Sensor
}

\author{
Younghoon $\mathrm{Cho}^{\dagger}$, Kwan-Yuhl Cho*, Hyungsoo Mok**, Kyeong-Hwa Kim***, and Jih-Sheng Lai ${ }^{\dagger}$ \\ $\dagger$ Dept. of Electrical and Computer Eng., Virginia Tech, Blacksburg, USA \\ * Dept. of Control and Instrumentation Eng., Chungju National University, Chungju, Korea \\ ** Dept. of Electrical Eng., Konkuk University, Seoul, Korea \\ *** Dept. of Electrical Eng., Seoul National University of Science and Technology, Seoul, Korea
}

\begin{abstract}
This paper proposes phase current reconstruction techniques for two-phase two-leg and two-phase four-leg inverters using a single current sensor. In the proposed methods, one phase current is sampled simultaneously with a particular branch current by using only one current sensor, and then current reconstruction algorithms are applied to extract the information on two phase currents from the sensor output. The sampled current information is periodically updated at the peak and the valley of the triangular carrier waveform in each switching cycle of pulse-width modulation (PWM). The voltage vector spaces where the phase currents can be reconstructed are evaluated. Compared to the existing method using two individual current sensors in two phases, the proposed schemes can save implementation cost since it is possible to remove one current sensor. In addition, the proposed methods are free from gain discrepancy issues between two current sensors. Simulations and experiments show excellent current reconstruction performance of the proposed methods.
\end{abstract}

Key Words: Current reconstruction, Two-phase four-leg inverters, Two-phase inverters, Two-phase two-leg inverters, Single current sensor technique

\section{INTRODUCTION}

Two-phase motor drives using two-phase two-leg or four-leg inverters have been studied in many low cost applications [1] [11]. The two-phase two-leg inverter is considered to be one of the more economic solutions for variable speed AC motor drives. In some low voltage applications such as a mobile robot and a stepping motor drive [5], [6], the two-phase fourleg inverter can be an attractive candidate because higher phase voltage output can be obtained compare with the three-phase half-bridge inverter operating under a fixed dc-link voltage condition [8]-[11].

Meanwhile, vector control theories in three-phase motor drives can be directly applied to two-phase motor drives [9]. Similar to three-phase systems, the information of all phase currents should be obtained in real-time to implement the vector controls in two-phase inverter-fed motor drives. One popular and possible solution to get the phase current information is using two individual current sensors for each of the two phases. However, using two individual current

Manuscript received Apr. 17, 2011; revised Aug. 11, 2011

Recommended for publication by Associate Editor Jang-Mok Kim.

$\dagger$ Corresponding Author: yhcho98@vt.edu

Tel: +1-540-808-6100, Virginia Tech

* Dept. of Control and Instrumentation Eng., Chungju National University, Korea

** Dept. of Electrical Eng., Konkuk University, Korea

*** Dept. of Electrical Eng., Seoul National University of Science and Technology, Korea sensors may not be an economic solution for a low cost drive application. On the other hand, if the output characteristics of the individual current sensors are not exactly matched, it causes torque ripples whose frequency is proportional to the electrical angular speed of the rotor [12]-[14].

The problems can be mitigated by using a single current sensor technique. In three-phase motor drive systems, many studies have been conducted to reconstruct three-phase currents by using a single current sensor [15]-[17]. However, only a few literatures are available for single current sensor technique in two-phase motor drive system [10].

In this paper, three single current sensor techniques are proposed for two-phase two-leg inverters [10] and two-phase four-leg inverters with bipolar and unipolar pulse-width modulation (PWM) scheme. In the proposed method, one phase current and a particular branch current are sampled simultaneously by using only one current sensor. After that, the current reconstruction algorithms are applied to reconstruct the two phase currents from the current sensor output. The proposed algorithms operate periodically at the peak and the valley of a triangular carrier waveform for PWM operation in every switching cycle. Dead-zones where it is impossible to reconstruct the phase currents are evaluated in the voltage vector spaces for two-phase inverters. Compared to the existing method using two individual current sensors in two phases, the proposed schemes can save implementation cost since it is possible to remove one current sensor. In addition, 


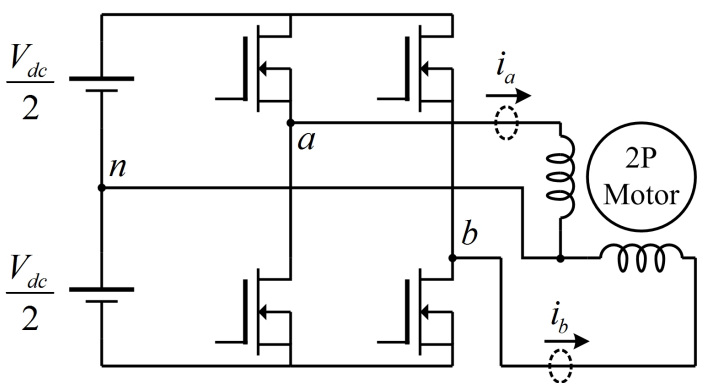

(a) Two-phase two-leg inverter.

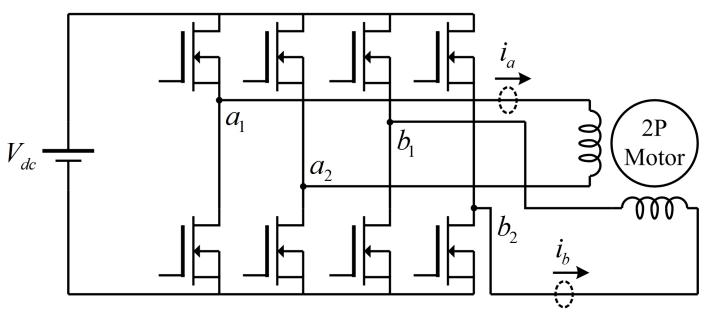

(b) Two-phase four-leg inverter.

Fig. 1. Two-phase inverter configurations for two-phase motor drives.

the proposed methods are free from gain discrepancy issues between two current sensors since only one current sensor is utilized. Simulations and experiments show excellent current reconstruction performance of the proposed methods.

\section{Two PHASE INVERTER}

Fig. 1(a) and 1(b) show two-phase motor drive systems configured by a two-phase two-leg and a two-phase four-leg inverter. When the two-phase two-leg inverter is used for the two-phase motor drive, the one side end-points of phase $a$ and phase $b$ are commonly connected to the neutral point of the separated $\mathrm{dc}$ sources while the other side end-points are connected to each of the switching legs as shown in Fig. 1(a).

If the two-phase four-leg inverter is employed for the two-phase motor drive, each of the end-points in the two windings is connected to the switching legs separately. The angle difference between phase $a$ and phase $b$ currents should be 90 degrees in normal operation. Accordingly, phase $a$ and phase $b$ can be compared to stationary reference $d-q$ frames in three-phase applications. By using this property, voltage vector spaces for two-phase two-leg and two-phase four-leg inverters are evaluated as shown in Fig. 2 [11].

In two-phase inverters, a modulation index can be defined as,

$$
M=\frac{V_{m}}{V_{d c}}
$$

where $V_{m}$ and $V_{d c}$ represent the peak value of the phase voltage reference and the dc-link voltage, respectively. In Fig. 2 , the maximum available linear modulation indexes are 0.5 for two-phase two-leg inverters and 1.0 for two-phase four-leg inverters according to (1). As illustrated in Fig. 2, when twophase inverters are utilizing its full capacities of the dc-link voltage, the inverters go into the four-step operation which is comparable to six-step operation in three-phase inverters.

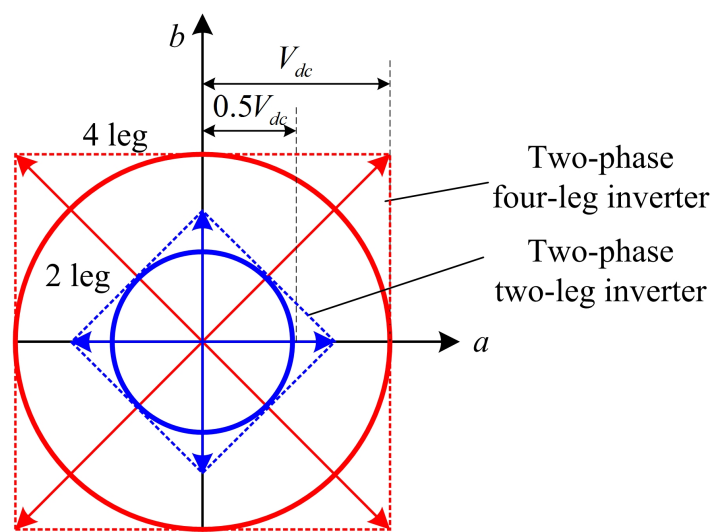

Fig. 2. Comparison of the voltage vector spaces in two-phase two-leg and four-leg inverters.

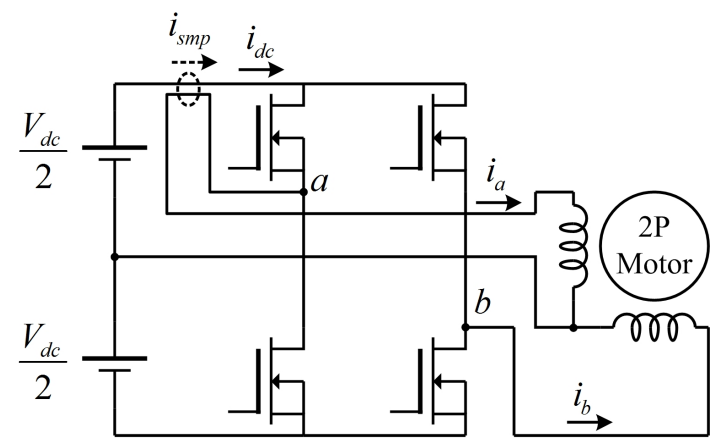

Fig. 3. Proposed sensor configuration method for two-phase two-leg inverter.

\section{Phase Current Reconstruction Methods}

Three types of phase current reconstruction methods are proposed for two-phase inverters in this section. In the proposed method, one phase current is measured together with a particular branch current by using a Hall-effect current sensor. After that, current reconstruction algorithms are applied to reconstruct both phase $\mathrm{a}$ and $\mathrm{b}$ currents in a PWM switching cycle. To do this, the following assumptions are required:

a) The load inductance is sufficiently large and the current through the load is approximately constant in a PWM switching cycle.

b) The current sensor output is sampled twice in a PWM switching cycle.

c) The bandwidth of the current sensor is fast enough to measure the chopped current accurately through the current sensor.

d) The proposed methods are implemented in a digital control scheme.

Based on these assumptions, the proposed methods will be described in the next subsections.

\section{A. Current Reconstruction Method for Two-Phase Two-Leg Inverter}

Fig. 3 shows a configuration method of the current sensor to implement the proposed single current sensor technique for two-phase two-leg inverters. In this method, a Hall-effect current sensor is used to measure both a phase current and the positive or the negative dc-bus current simultaneously. In this paper, phase $a$ and the positive bus currents are sampled 


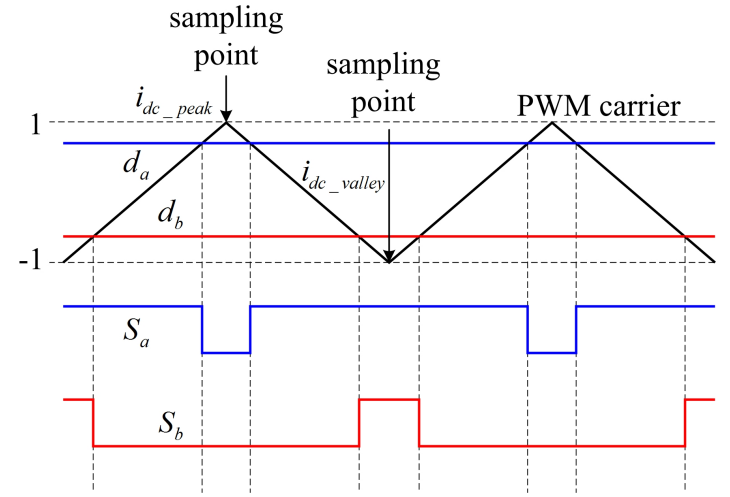

Fig. 4. Current sampling points in the proposed method.

arbitrarily. Accordingly, the output value of the current sensor $i_{s m p}$ is,

$$
i_{s m p}=i_{d c}-i_{a}
$$

where $i_{d c}$ and $i_{a}$ represent the positive dc-bus and phase $a$ currents. Next, the switching function for the two-phase twoleg inverter is defined as follows.

$$
\begin{aligned}
& S\left(S_{a}, S_{b}\right) ; \\
& S_{a}: \text { phase a switching state } \in\{0,1\} \\
& S_{b}: \text { phase b switching state } \in\{0,1\} \\
& 1: \text { upper switch turn on } \\
& 0: \text { lower switch turn on }
\end{aligned}
$$

The relationship between the PWM carrier waveform and the current sampling points is shown in Fig. 4. A triangular waveform is considered as the PWM carrier to obtain the two switching functions, $S(0,0)$ and $S(1,1)$, at the peak and the valley of the PWM carrier. The maximum and the minimum values of the PWM carrier are limited by 1 and -1 . The phase $a$ and $b$ duties are represented as $d_{a}$ and $d_{b}$, respectively. The duty references ranges within the maximum and the minimum values of the PWM carrier. The output of the current sensor $i_{s m p}$ is sampled at both the peak and the valley of the PWM carrier by using the analog-to-digital (AD) converter of the digital controller.

The sampled current at the peak of the PWM carrier where the switching function is $S(0,0)$ is defined as $i_{d c_{-} p e a k}$, while the sampled current at the valley of the PWM carrier where the switching function is $S(1,1)$ is defined as $i_{d c_{-} \text {valley }}$. Fig. 5 shows the commutation modes at the peak and the valley points of the PWM carrier. In Fig. 5(a), the positive dc-bus does not supply a current to any phase and only phase $a$ current is measured by the current sensor. Therefore, at this point, the current sensor output is,

$$
i_{s m p}=i_{d c}-i_{a s}=-i_{a}
$$

From (4), $i_{d c_{-} \text {peak }}$ is,

$$
i_{d c \_p e a k}=-i_{a}
$$

Fig. 5(b) describes the commutation mode at the valley point in the PWM carrier. As shown in the figure, both phase $a$ and $b$ currents are flowing through the positive dc-bus. Hence, $i_{d c}$ is represented as following.

$$
i_{d c}=i_{a}+i_{b}
$$

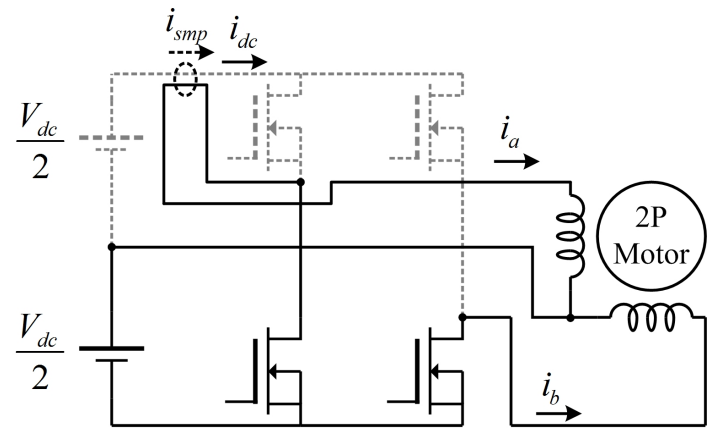

(a) At the peak point of the PWM carrier, $S(0,0)$.

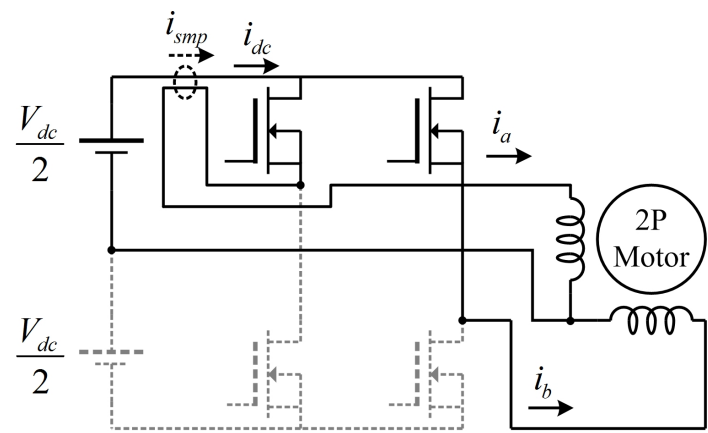

(b) At the valley point of the PWM carrier, $S(1,1)$.

Fig. 5. Commutation modes at the peak and valley points in the PWM carrier waveform.

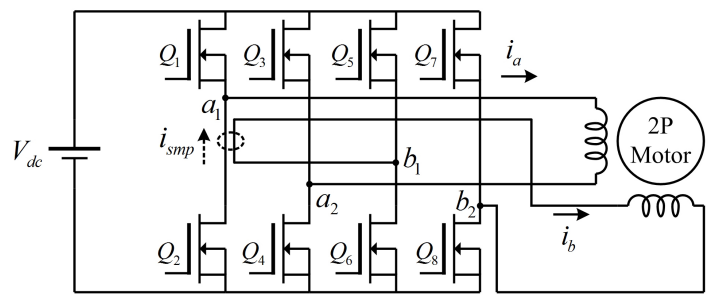

Fig. 6. Proposed current sensor configuration for two-phase four-leg inverter with unipolar PWM.

From (2) and (6), $i_{s m p}$ is,

$$
i_{s m p}=i_{d c}-i_{a}=\left(i_{a}+i_{b}\right)-i_{a}=i_{b}
$$

Then, $i_{d c_{-} v a l l e y}$ is,

$$
i_{d c_{-} \text {valley }}=i_{b}
$$

By using (5) and (8), phase $a$ and $b$ currents are reconstructed as following.

$$
\begin{aligned}
& i_{a}=-i_{d c_{-} \text {peak }} \\
& i_{b}=i_{d c_{-} \text {valley }}
\end{aligned}
$$

As long as the duty references are not over 1 or -1 , both the switching functions $S(0,0)$ and $S(1,1)$ appear in a PWM switching cycle. However, duty references rarely reach 1 or -1 in most inverter applications. In practice, there are some cases where commanding 1 or -1 as a duty reference is not even impossible due to hardware limitations. A later section will cover the issue. 


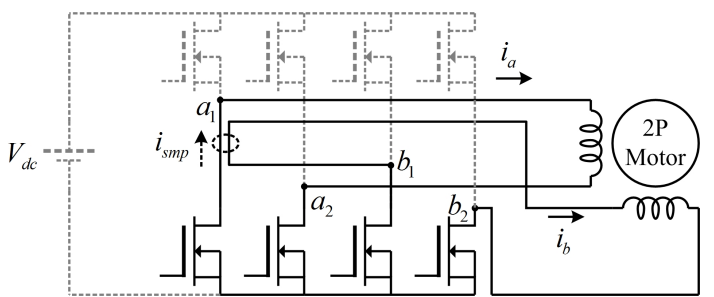

(a) $S(0,0,0,0)$.

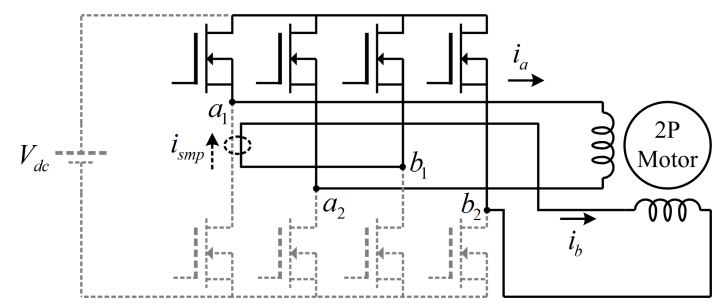

(b) $S(1,1,1,1)$.

Fig. 7. Commutation modes at the peak and the valley points with unipolar PWM scheme.

\section{B. Current Reconstruction Method for Two-Phase Four-Leg Inverter with Unipolar PWM}

Two kinds of phase current reconstruction methods are proposed for two-phase four-leg inverters depending on PWM schemes. One method is for unipolar PWM scheme and another is for bipolar PWM scheme. The reason for proposing two methods is that the commutation modes during the free-wheeling period are different in each of the PWM schemes. This subsection proposes a phase current reconstruction method for two-phase four-leg inverters with unipolar PWM scheme. Fig. 6 shows the current sensor configuration method for the proposed method. In Fig. 6, phase $a$ consists of phase $a_{1}$ and $a_{2}$, while phase $b$ consists of phase $b_{1}$ and $b_{2}$. A Hall-effect current sensor is employed to measure both phase $b$ current and the branch between $Q_{1}$ and $Q_{2}$ which is the middle of the switching leg of phase $a_{1}$. Again, this configuration is chosen to demonstrate the proposed method arbitrarily. Other configurations are also available. Similar to the two-leg case, the switching function is also defined as (10) for the two-phase four-leg inverter.

$S\left(S_{a 1}, S_{a 2}, S_{b 1}, S_{b 2}\right)$;

$S_{a 1}$ : phase $a_{1}$ switching state $\in\{0,1\}$

$S_{a 2}$ : phase $a_{2}$ switching state $\in\{0,1\}$

$S_{b 1}:$ phase $b_{1}$ switching state $\in\{0,1\}$

$S_{b 2}:$ phase $b_{2}$ switching state $\in\{0,1\}$

1 : upper switch turn on

0 : lower switch turn on

In the unipolar PWM scheme, the duty references of phase $a_{1}, a_{2}, b_{1}$, and $b_{2}$ are given by,

$$
\begin{array}{ll}
d_{a 1}=d_{a}^{*} & d_{a 2}=-d_{a}^{*} \\
d_{b 1}=d_{b}^{*} & d_{b 2}=-d_{b}^{*}
\end{array}
$$

where $d^{*}{ }_{a}$ and $d^{*}{ }_{b}$ represent the duty references of phase $a$ and $b$. If the duty references are used with the triangular PWM carrier as in Fig. 4 and the magnitudes of the duty references are within the range of -1 and 1 , the switching functions at the peak and the valley of the PWM carrier become $S(0,0,0,0)$ and

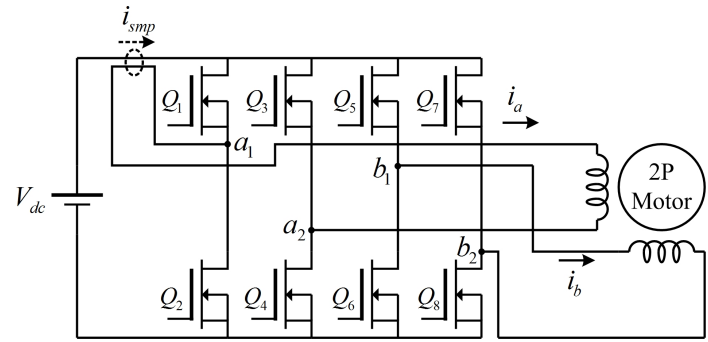

Fig. 8. Proposed current sensor configuration for two-phase four-leg inverter with bipolar PWM.

$S(1,1,1,1)$. Fig. 7 shows the commutation modes in these cases. Similar to the previous two-phase two-leg case, the sampled current at the peak of the PWM carrier where the switching function is $S(0,0,0,0)$ is defined as $i_{d c_{-} p e a k}$, while the sampled current at the valley of the PWM carrier where the switching function is $S(1,1,1,1)$ is defined as $i_{d c \text { valley. As shown in Fig. }}$ 7 (a), if the switching function is $S(0,0,0,0)$, the current sensor measures both phase $b$ and the middle of phase $a_{1}$ branch currents. Because the phase $a_{1}$ branch current is identical to phase $a$ current at $S(0,0,0,0)$, the current sensor output is,

$$
i_{s m p}=i_{a}+i_{b}
$$

Then, $i_{d c_{-} \text {peak }}$ is,

$$
i_{d c_{-} \text {peak }}=i_{a}+i_{b}
$$

Meanwhile, as shown in Fig. 7(b), the current sensor only measures phase $b$ current at the switching function $S(1,1,1,1)$ as following.

$$
i_{s m p}=i_{b}
$$

Then, $i_{d c_{-} v a l l e y}$ is,

$$
i_{d c_{-} \text {valley }}=i_{b}
$$

From (13) and (15), phase currents $a$ and $b$ are reconstructed as following.

$$
\begin{aligned}
& i_{b}=i_{d c_{-} \text {valley }} \\
& i_{a}=i_{d c_{-} \text {peak }}-i_{d c_{-} \text {valley }}
\end{aligned}
$$

\section{Current Reconstruction Method for Two-Phase Four-Leg Inverter with Bipolar PWM}

The proposed single current sensor technique for two-phase four-leg inverters with bipolar PWM scheme is shown in Fig. 8. In this method, a Hall-effect current sensor is used to measure both phase $a$ current and the positive dc-bus current at the same time, similar to the two-phase two-leg case. If a triangular waveform is chosen as the PWM carrier in the bipolar PWM scheme, the switching function at the peak and the valley of the PWM carrier become $S(0,1,0,1)$ and $S(1,0,1,0)$. Similar to the two-phase four-leg case, the sampled currents at the peak and the valley of the PWM carrier are defined as $i_{d c_{-} \text {peak }}$ and $i_{d c_{-} \text {valley }}$. Fig. 9 shows the commutation mode at the peak and the valley points of the triangular PWM carrier in this case. As illustrated in Fig. 9(a), when the switching function is $S(0,1,0,1)$, the positive dc-bus current $i_{d c}$ takes phase currents $a$ and $b$ according to the directions defined in the figure. However, it should be noted that physical 


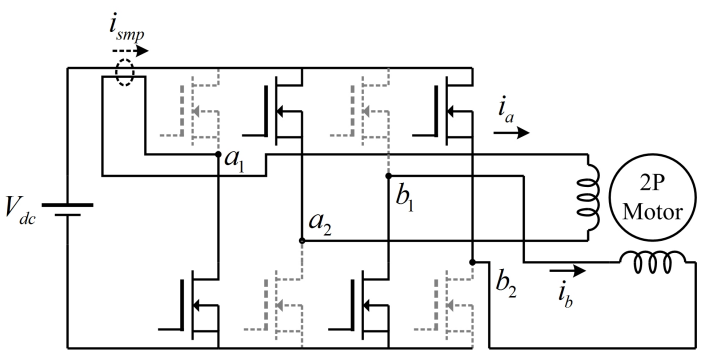

(a) $S(0,1,0,1)$.

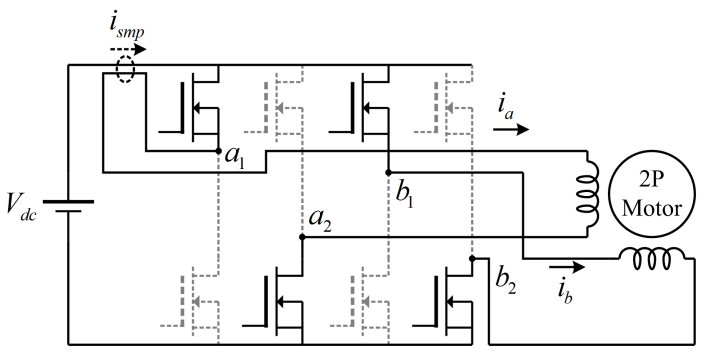

(b) $S(1,0,1,0)$.

Fig. 9. Commutation mode at the peak and the valley points with bipolar PWM scheme.

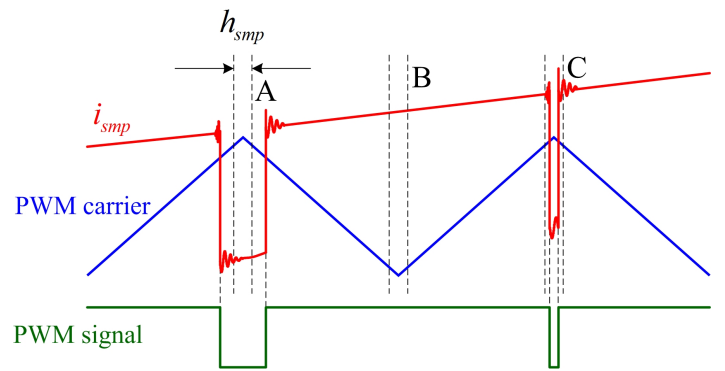

Fig. 10. Minimum sampling interval.

currents can be either taken or supplied by $i_{d c}$ according to the direction of the actual phase currents. Here the current sensor output can be written as,

$$
i_{s m p}=i_{d c}-i_{a}=\left(-i_{a}-i_{b}\right)-i_{a}=-2 i_{a}-i_{b}
$$

Then, $i_{d c_{-} \text {peak }}$ is,

$$
i_{d c_{-} p e a k}=-2 i_{a}-i_{b}
$$

If the switching function is $S(1,0,1,0)$ as shown in Fig. 9(b), the positive dc-bus current $i_{d c}$ supplies both phase $a$ and $b$ currents according to the defined directions. Hence the current sensor output $i_{s m p}$ is,

$$
i_{s m p}=i_{d c}-i_{a}=\left(i_{a}+i_{b}\right)-i_{a}=i_{b}
$$

Then, $i_{d c_{-} \text {valley }}$ is,

$$
i_{d c_{-} \text {valley }}=i_{b}
$$

From (17) and (20), both phase $a$ and $b$ currents can be reconstructed as follows.

$$
\begin{aligned}
& i_{b}=i_{d c_{\text {_valley }}} \\
& i_{a}=-\frac{i_{d c_{\text {_peak }}}+i_{d c_{-} \text {valley }}}{2}
\end{aligned}
$$

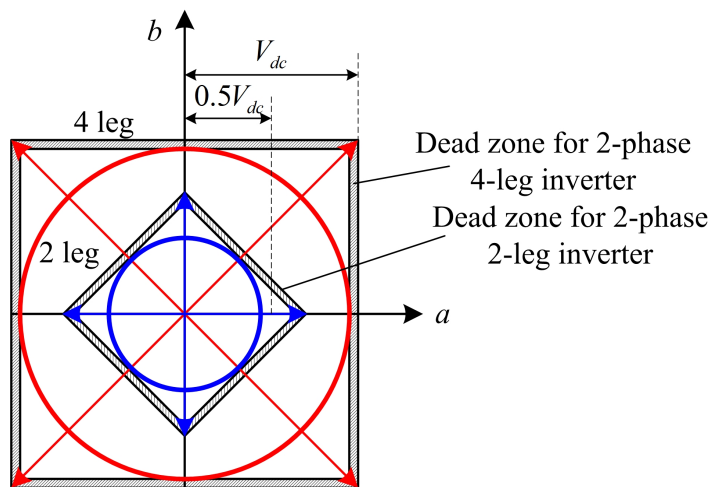

Fig. 11. Comparison of the voltage vector spaces in two-phase two-leg and four-leg inverters considering dead-zones.

\section{DeAD-ZOne Analysis}

Although the proposed methods clearly show the possibilities of single current sensor techniques for two-phase inverters in theory, there are some practical limitations to be considered such as $\mathrm{AD}$ conversion time, switching noise components, and so on. Due to these limitations, a minimum sampling interval $h_{s m p}$ is defined. The length of the minimum sampling interval depends on the current settling time near the current sampling points and sampling and hold time of the AD converter. Fig. 10 shows the relationship between the duty reference and $h_{s m p}$. The minimum sampling interval $h_{s m p}$ is necessary for every sampling instant. At the points A and B in Fig. 10, $i_{s m p}$ is settled to steady state before the minimum sampling interval. Therefore the average current can be easily sampled through the $\mathrm{AD}$ converter in the digital controller. However, at point $\mathrm{C}$ in Fig. 10, $i_{s m p}$ is still under transients due to switching noise and parasitics. Here, the minimum sampling interval cannot be satisfied. As a result, the $\mathrm{AD}$ conversion at this point may be incomplete and inaccurate.

The minimum sampling interval should therefore be guaranteed in a PWM switching cycle. With the triangular PWM carrier in the proposed methods, guaranteeing $h_{s m p}$ becomes harder as the phase duty references approach the positive or the negative maximum value, 1 and -1 . This means that the maximum available voltage under the fixed dc-link voltage condition is reduced. In fact, this effect becomes more dominant as the switching frequency increases. For example, suppose that $h_{s m p}$ is selected to be $2 \mu$ sec by considering AD conversion time and decaying switching noise under 5-kHz of the switching frequency. In this case, the maximum and the minimum duty periods are limited to $198 \mu \mathrm{sec}$ and $2 \mu \mathrm{sec}$. Therefore the inverter has a total of $4 \mu \mathrm{sec}$ of dead-zone. This means that equivalently 2 percent of the dc-link voltage cannot be utilized. If the switching frequency is $5-\mathrm{kHz}, 4 \mu \mathrm{sec}$ of the dead-zone is equivalently 4 percent of the dc-link voltage. Fig. 11 compares the voltage vector spaces for two-phase two-leg and four-leg inverters considering the dead-zones. As shown in the figure, the voltage vector spaces are limited to guarantee $h_{s m p}$. It should be noted that the dead zones appear when the voltage references approach the maximum value at a fixed dc-link voltage. However, practically, the effect of the dead zones caused by the proposed method to guarantee $h_{s m p}$ is not so high. In most inverter applications, a dead-time to prevent 


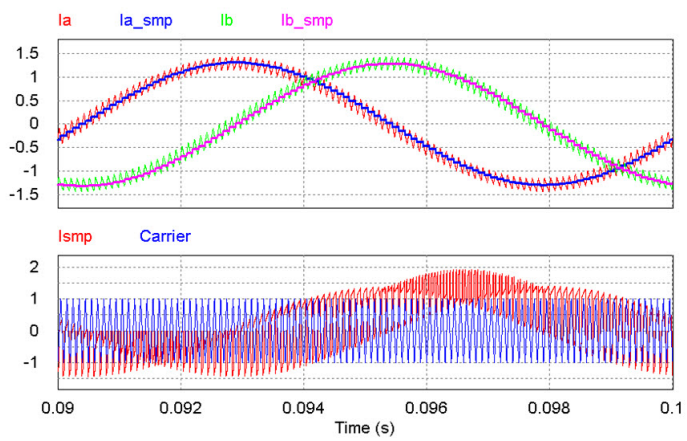

(a) $i_{a}, i_{a_{-} s m p}, i_{b}, i_{b_{-} s m p}, i_{s m p}$, and PWM carrier.
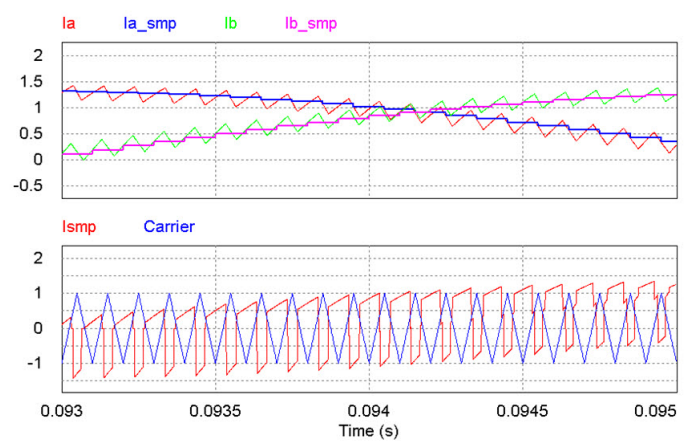

(b) $i_{a}, i_{a_{-} s m p}, i_{b}, i_{b_{-} s m p}, i_{s m p}$, and PWM carrier (zoomed in).

Fig. 12. Simulation result for two-phase two-leg inverter.

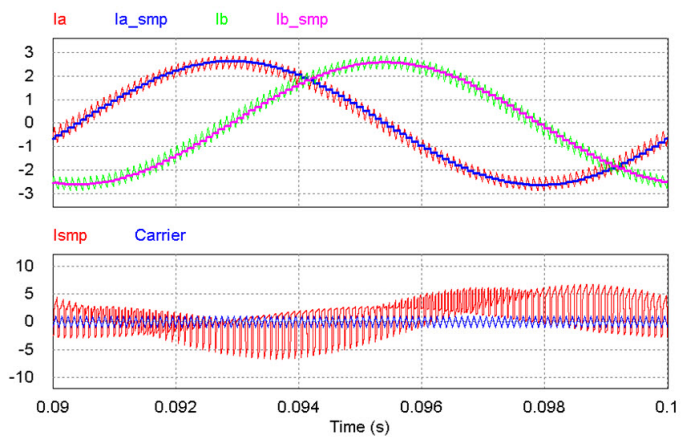

(a) $i_{a}, i_{a_{-} s m p}, i_{b}, i_{b_{-} s m p}, i_{s m p}$, and PWM carrier.
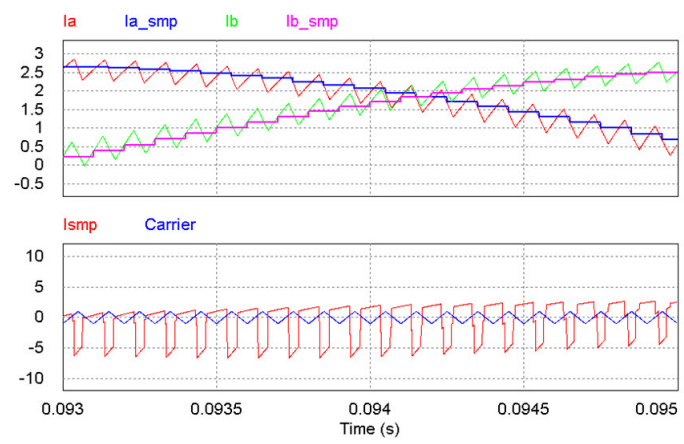

(b) $i_{a}, i_{a_{-} s m p}, i_{b}, i_{b_{-} s m p}, i_{\text {smp }}$, and PWM carrier (zoomed in).

Fig. 13. Simulation result for two-phase four-leg inverter with bipolar PWM.

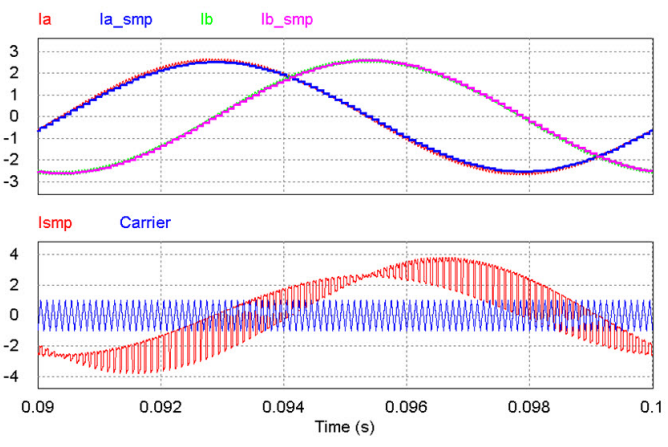

(a) $i_{a}, i_{a_{-} s m p}, i_{b}, i_{b_{-} s m p}, i_{s m p}$, and PWM carrier.
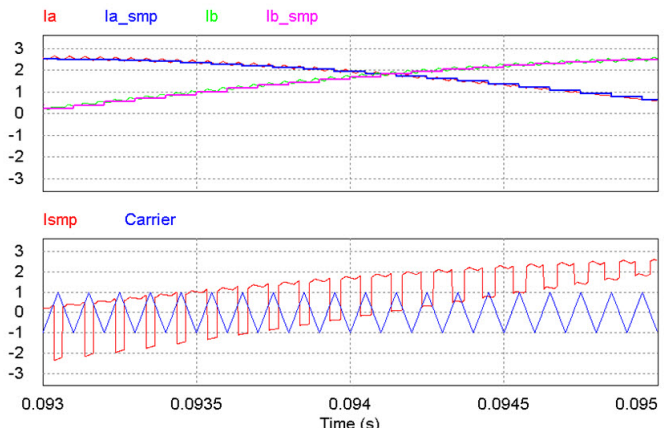

(b) $i_{a}, i_{a_{-} s m p}, i_{b}, i_{b_{-} s m p}, i_{s m p}$, and PWM carrier (zoomed in).

Fig. 14. Simulation result for two-phase four-leg inverter with unipolar PWM.

a shoot-through condition in a switching leg is necessary. Usually the dead-time is several $\mu \mathrm{sec}$. Therefore, regardless of the dead-zones in the proposed method, the maximum voltage output is limited by the dead-time. A different reason may dominate in a low cost drive system. In these systems, it is popular to use bootstrap type gate drivers where bootstrap capacitors should be continuously charged. To do this, the lower switching device in a switching leg should be turned on at least several $n \mathrm{sec}$ to $\mu \mathrm{sec}$ in a PWM switching cycle. This will also limit the maximum duty reference. Because the maximum duty reference is already limited by both the dead-time and the bootstrap capacitor charging operation, the voltage limitation effect of $h_{s m p}$ is not a big deal.

\section{Simulation}

Simulations are carried out to evaluate the validity of the proposed methods based on PSIM software. The parameters used in the simulations are listed in Table I. The same parameters are applied for the two-phase two-leg, four-leg with unipolar PWM scheme, and four-leg with bipolar PWM scheme simulations. As listed in the table, the sinusoidal duty references have a modulation index of 0.5 and a fundamental frequency of $100-\mathrm{Hz}$. These references are applied in openloop. In all of the simulation results, $i_{a}, i_{b}, i_{a_{-} s m p}, i_{b_{-} s m p}$, and $i_{\text {smp }}$ represent the actual phase current $a$ and $b$, the reconstructed phase currents $a$ and $b$, and the current sensor output. Fig. 12 shows the simulation result of the proposed 


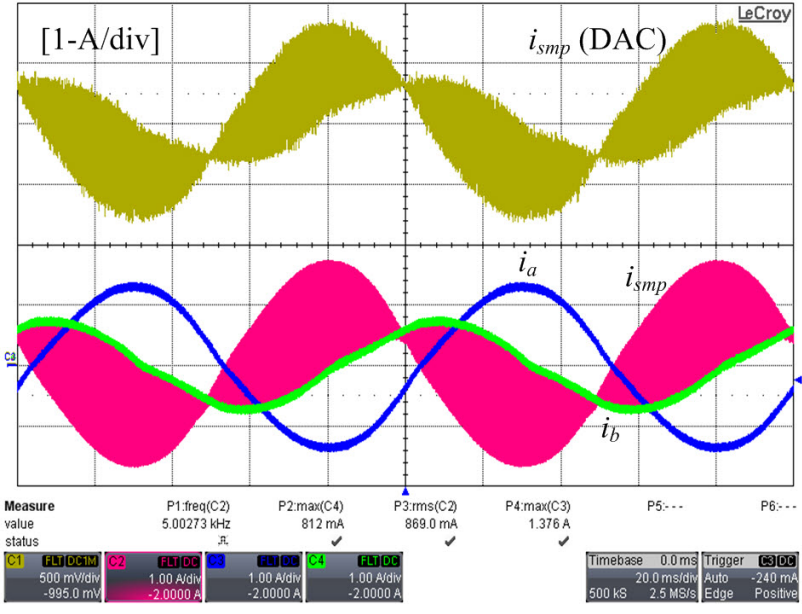

(a) $i_{a}, i_{b}, i_{s m p}$, and sampled $i_{s m p}$

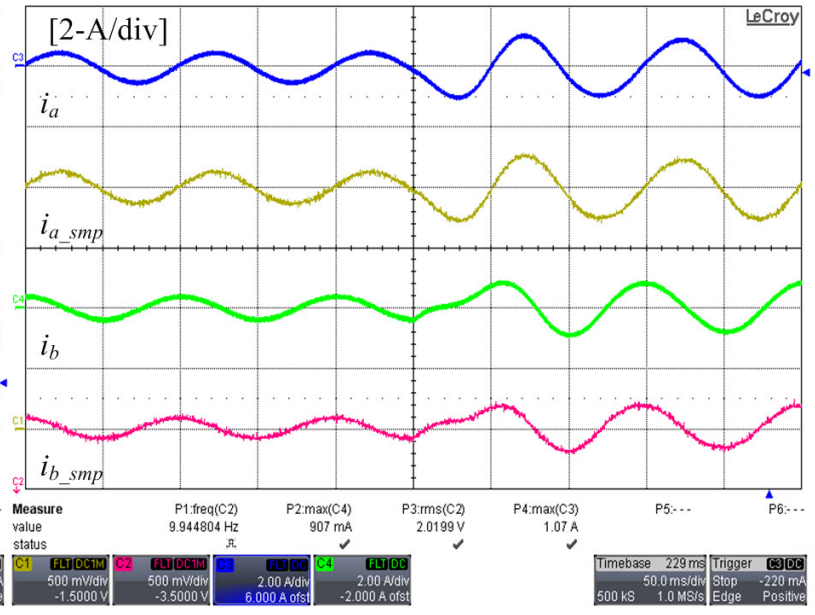

(b) $i_{a}, i_{a_{-} s m p}, i_{b}$, and $i_{b_{-} s m p}$

Fig. 15. Experimental result for two-phase two-leg inverter.

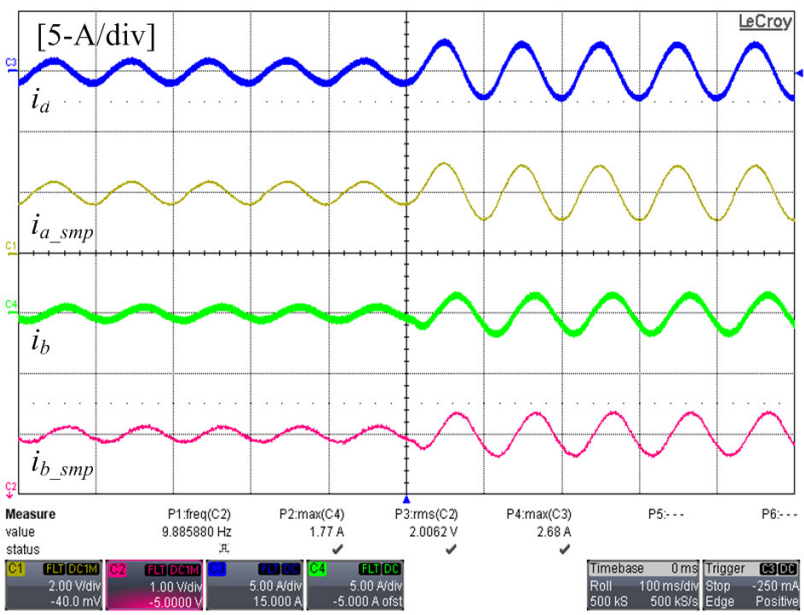

(a) $i_{a}, i_{b}, i_{s m p}$, and $i_{b_{-} s m p}$

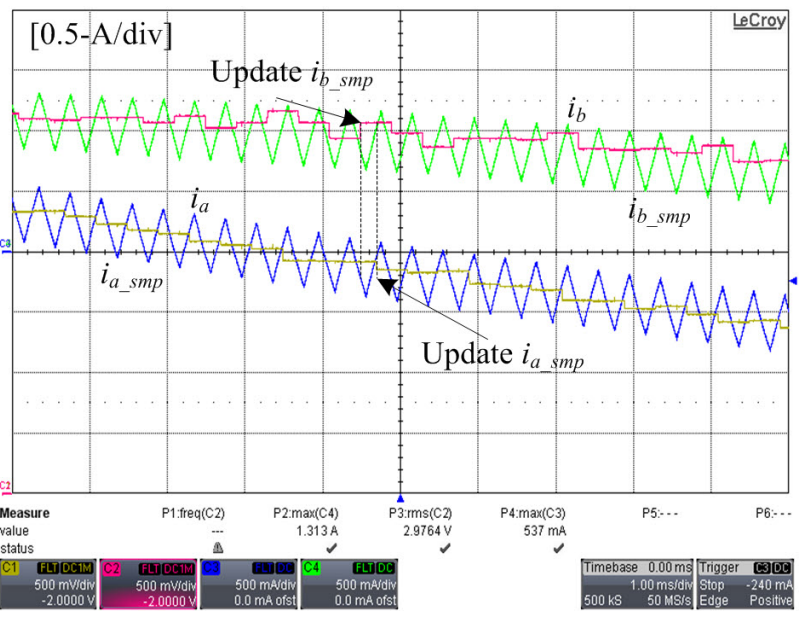

(b) $i_{a}, i_{a_{-} s m p}, i_{b}$, and $i_{b_{-} s m p}$ (zoomed-in)

Fig. 16. Experimental result for two-phase four-leg inverter with bipolar PWM.

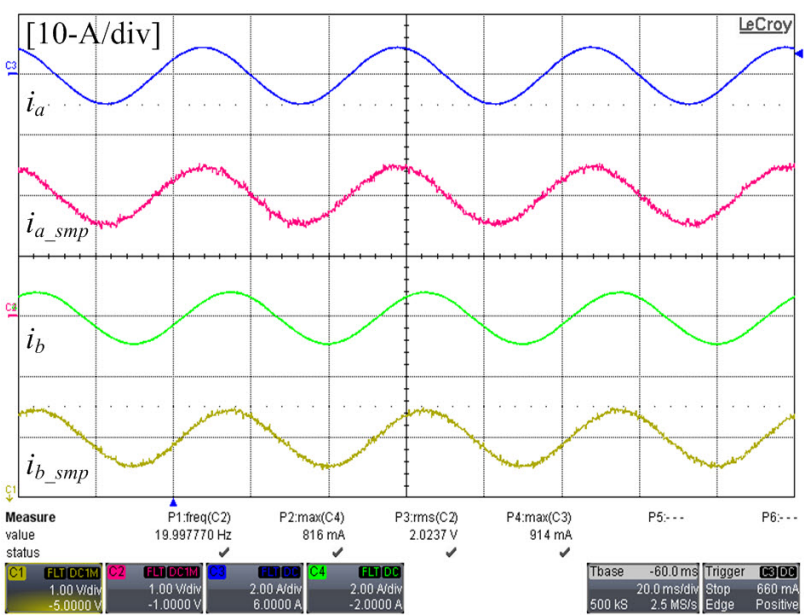

(a) $i_{a}, i_{b}, i_{s m p}$, and sampled $i_{s m p}$

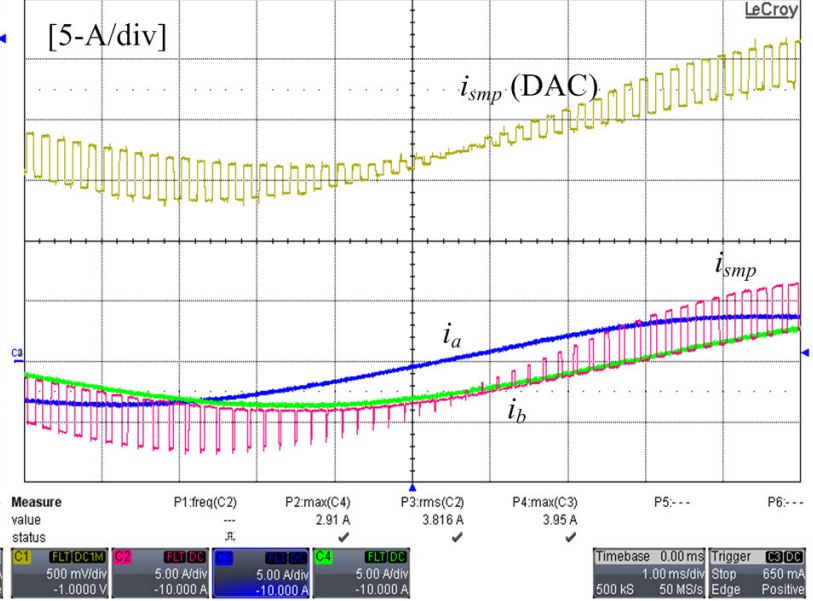

(b) $i_{a}, i_{b}, i_{s m p}$, and $i_{s m p}(\mathrm{DAC})$

Fig. 17. Experimental result for two-phase four-leg inverter with unipolar PWM. 
method for the two-phase two-leg inverter. The simulation results of the proposed method for the two-phase four-leg with unipolar and bipolar PWM schemes are shown in Fig. 13 and 14. As can be seen in the figures, the actual and the reconstructed phase currents are well matched in the proposed methods. In Fig. 12 and 13, the current reconstruction and the switching ripple periods are identical. However, as can be seen in Fig. 14, the period of the switching ripple is twice that of the current reconstruction interval since the effective switching frequency is double the frequency of the PWM carrier in unipolar PWM scheme.

\section{EXPERIMENTS}

Experiments are carried out to show the effectiveness of the proposed methods. For the experiments, the same parameters with the simulations are used as in Table I. The proposed algorithms are implemented with a digital control board in which TI's TMS320F28335 digital signal processor (DSP) is employed. By using a 4-channel digital-to-analog converter, the DSP internal variables are monitored in real-time. As the current sensor, LEM's LA55-P is used. The bandwidth of the sensor is $200-\mathrm{kHz}$. The PWM output voltages are applied in open-loop manner.

Fig. 15 shows the experimental result of the proposed single current sensor technique for the two-phase two-leg inverter case. In Fig. 15(a), $i_{a}, i_{b}$, and $i_{s m p}$ are measured by using the current probes of the oscilloscope. By using the DAC, $i_{s m p}$ is monitored as $i_{s m p}$ (DAC). As can be seen in the figure, $i_{s m p}(\mathrm{DAC})$ reflects $i_{s m p}$ very well without severe noise components. Unlike the previous simulation result, the magnitude of the two phase currents are different because the capacitor voltage is fluctuating due to the neutral phase current in two-phase two-leg inverter. The reconstructed phase $a$ and $b$ currents are shown in Fig. 15(b). It can be seen that the measured and the reconstructed currents are well matched even in transient.

Fig. 16(a) compares the actual and the reconstructed phase currents for two-phase four-leg inverter with bipolar PWM case. Fig. 16(b) shows the zoomed-in waveforms of the actual and the reconstructed phase currents near a zero crossing point of $i_{a}$. In every sampling points, phase $a$ and phase $b$ currents are updated by turns, and this shows a good agreement with the theoretical analyses of the proposed method.

Fig. 17 shows the experimental results for two-phase fourleg inverter case with unipolar PWM method. As shown in Fig. 17(a), the phase current reconstruction is well performed. In Fig. 17(b), it can be seen that the sampled value of $i_{s m p}$ exactly matches with the actual $i_{s m p}$ with the half sample delay due to double update of the current sampling.

Fig. 18 shows the test result when the output voltage modulation index is 1.0. In this case, the reconstructed phase currents are distorted because the minimum sampling interval which is explained in section IV is not guaranteed, and the voltage reference vectors locate in the dead-zone. Therefore, it is crucial to secure the minimum sampling interval in the implementation of the proposed methods.

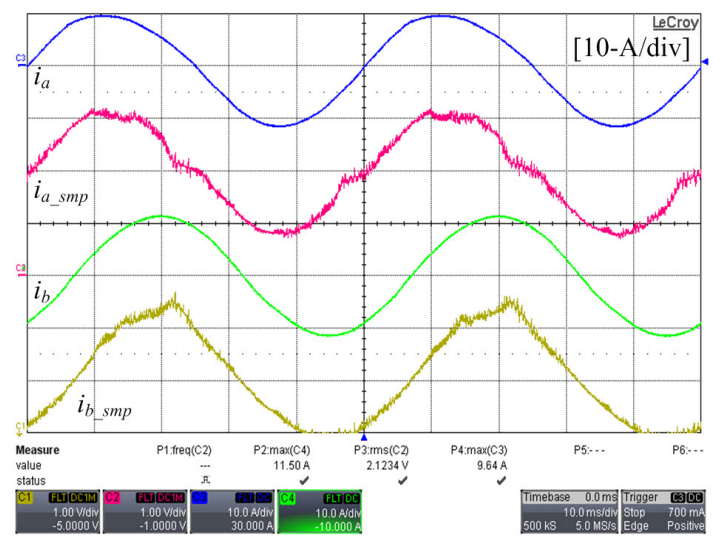

Fig. 18. Experimental result for two-phase four-leg inverter with unipolar PWM when the output modulation index is 1.0.

\section{CONCLUSION}

In this paper, three single current sensor techniques are proposed for two-phase two-leg inverter, two-phase four-leg inverter with bipolar PWM, and two-phase four-leg inverter with unipolar PWM. In the proposed methods, a phase current is sampled simultaneously with a particular branch current by using only one current sensor. After that, the phase current reconstruction algorithms are applied to get two-phase current information. This operation is occurred periodically in the proposed method. This is an important advantage of the proposed method to be implemented by using a digital controller. Additionally, this regular sampling feature gives another advantage that the sampled currents are identical to the average value of each phase current. From the dead-zone analysis, the limitations of the proposed method are addressed. Finally, the simulation and the experimental results show that the proposed single current sensor technique can reconstruct two-phase current in two-phase two-leg and two-phase four leg inverters.

\section{REFERENCES}

[1] F. Blaabjerg, F. Lungeanu, K. Skaug, and M. Tonnes, "Two-phase induction motor drives," IEEE IA Magazine, pp. 24-32, Jul./Aug. 2004.

[2] D. G. Holmes and A. Kotsopoulos, "Variable speed control of single and two phase induction motors using a three phase voltage source inverter," in Conf. Rec. IEEE/IAS Annual Meeting, Vol. 1, pp.613-620, 1993.

[3] I. R. Smith, G. Creighton, and L. M. C. Mhango, "Analysis and performance of a novel two-phase drive for fan and water-pumping applications," IEEE Trans. Ind. Electron., Vol. 36, No. 4, pp. 530-538, Nov. 1989.

[4] C. B. Jacobina, E. C. dos Santos, M. B. R. Correa, and E. R. C. da Silva, "Reduced Switch Count AC-AC Two-Phase Drive Systems," In Proc. PESC'05, pp. 687-693, 2005.

[5] N. Matsui, M. Nakamura, and T. Kosaka, "Instantaneous torque analysis of hybrid stepping motor," IEEE Trans. Ind. Applicant., Vol. 32, No. 5, pp. 1241-1253, Sep./Oct. 1996.

[6] Y.-K. Kim, Y.-H. Cho, N.-C. Park, S.-H. Kim, and H.-S. Mok, "Inwheel motor drive system using 2-phase pmsm," In proc. IPEMC'09, pp.1875-1879, 2009.

[7] M. A. Jabbr, M. K. Ashwin, and Z. Yangfeng, "Space-vector modulation in a two-phase induction motor drive for constant-power operation," IEEE Trans. Ind. Electron., Vol. 51, No. 5, pp. 1081-1088, Oct. 2004.

[8] D.-H. Jang and D. Y. Yoon, "Space-vector pwm technique for two-phase inverter-fed two-phase induction motors," IEEE Trans. Ind. Applicant., Vol. 39, No. 2, pp.542-549, Mar./Apr. 2003.

[9] D.-H. Jang and Y.-H. Cho, "Vector control for two-phase inverter-fed two-phase induction motors," The Transactions of Korean Institute of Power Electronics, Vol. 12, No. 4, pp.310-317, Aug. 2007. 
[10] Y.-H. Cho, H.-S. Mok, D.-H. Jang, and S.-H. Kim, "A novel current measurement method for two-phase half-bridge inverter using single current sensor," in KIPE Power Electronics Annual Conference, pp.193195, Jul. 2007.

[11] D.-H. Jang, "PWM methods for two-phase inverters," IEEE IA Magazine, Vol. 13, No. 2, pp. 50-61, Mar./Apr. 2007.

[12] D.-W. Chung and S.-K. Sul, "Analysis and compensation of current measurement error in vector-controlled ac motor drives," IEEE Trans. Ind. Applicant., Vol. 34, No. 2, pp.340-345, Mar./Apr. 1998.

[13] H.-S. Jung, S.-H. Hwang, J.-M. Kim, C.-U. Kim, and C. Choi, "Diminution of current-measurement error for vector-controlled ac motor drives," IEEE Trans. Ind. Applicant., Vol. 42, No. 5, pp.1249-1256, Sep./Apr. 2006.

[14] G.-G. Park, S.-H. Hwang, J.-M. Kim, K.-B. Lee, and D.-C. Lee, "Reduction of current ripples due to current measurement errors in a doubly fed induction generator," Journal of Power Electronics, Vol. 10, No. 3, pp. 313-319, May 2010.

[15] F. Blaabjerg, J. K. Pedersen, U. Jaeger, and P. Thoegersen, "Single current sensor technique in the dc link of three-phase pwm-vs inverters: a review and a novel solution," IEEE Trans. Ind. Applicant., Vol. 33, No. 5, pp. 1241-1253, Sep./Oct. 1997.

[16] J.-I. Ha, "Current prediction in vector-controlled pwm inverters using single dc-link current sensor," IEEE Trans. Ind. Electron., Vol. 57, No. 2, pp. 716-726, Feb. 2010.

[17] H. Kim, and T. M. Jahns, "Phase current reconstruction for ac motor drives using a dc link single current sensor and measurement voltage vectors," IEEE Trans. Power Electron., Vol. 21, No. 5, pp. 1413-1419, Sep. 2006.

[18] LAH 50-P datasheet, LEM, 2007.

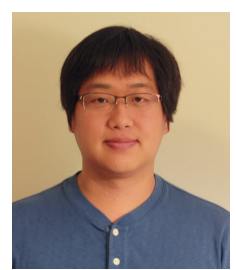

Younghoon Cho was born in Seoul, Korea, in 1980. $\mathrm{He}$ received the B.S. degree in electrical engineering from Konkuk University, Seoul, Korea, in 2002, and the M.S. degree in electrical engineering from Seoul National University, Seoul, in 2004. He is currently working toward the Ph.D. degree at Virginia Polytechnic Institute and State University, Blacksburg, VA. From 2004 to 2009, he was an Assistant Research Engineer at Hyundai MOBIS R\&D Center, Yongin, Korea. His current research interests include digital control techniques for power electronic converters in vehicle and grid applications, multilevel converters, and high performance motor drives.

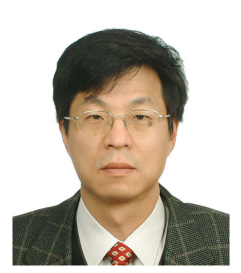

Kwan-Yuhl Cho received his B.S. in Electrical Engineering from Seoul National University, Seoul, Korea, in 1986, and his M.S. and Ph.D. in Electrical and Electronic Engineering from the Korea Institute of Science and Technology (KAIST), Daejon, Korea, in 1988 and 1993, respectively. He worked for the LG Electronics, Digital Appliance Research Lab., from 1993 to 2004. Since 2004, he has been with the Department of Control and Instrumentation Engineering at Chungju National University, Korea. His research interests include variable speed motor drives and power converters. He is a member of the Korean Institute of Power Electronics (KIPE) and a Publication Editor of the Journal of Power Electronics (JPE).

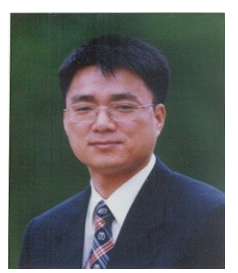

Hyungsoo Mok received the B.S., M.S. and Ph.D. degrees in electrical engineering from Seoul National University, Korea, in 1986, 1988, and 1992, respectively. He was with the Department of Control and Instrumentation Engineering at Seoul National Polytechnic University from 1993 to 1997. Since 1997, he has been with the Department of Electrical Engineering at Konkuk University. His teaching and research interests include electric machines, electric machine drive systems, and power electronic control for industrial and power systems.

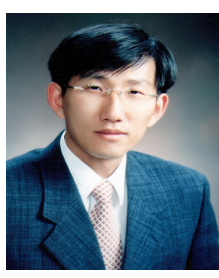

Kyeong-Hwa Kim was born in Seoul, Korea, in 1969 $\mathrm{He}$ received the B.S. degree from Hanyang University, Seoul, Korea, and the M.S. and Ph.D. degrees from KAIST, Taejon, Korea, in 1991, 1993, and 1998 , respectively, all in electrical engineering. From 1998 to 2000, he was a Research Engineer with Samsung Electronics Company, where he was engaged in research and development of AC machine drive systems. From 2000 to 2002, he was a Research Professor with KAIST. Since August 2002, he has been with Seoul National University of Science and Technology, where he is currently an Associate Professor. His current research interests are in the areas of AC machine drive, control, diagnosis, and DSP-based control applications. Prof. Kim is a member of the Korean Institute of Power Electronics (KIPE).

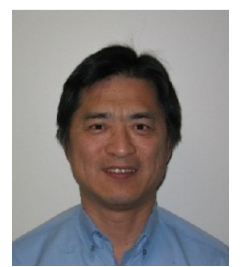

Jih-Sheng Lai received M.S. and Ph.D. degrees in electrical engineering from the University of Tennessee, Knoxville, in 1985 and 1989 respectively. From 1980 to 1983 , he was the Head of the Electrical Engineering Department of the Ming-Chi Institute of Technology, Taipei, Taiwan, where he initiated a power electronics program and received a grant from his college and a fellowship from the National Science Council to study abroad. In 1986, he became a staff member at the University of Tennessee, where he taught control systems and energy conversion courses. In 1989, he joined the Electric Power Research Institute (EPRI) Power Electronics Applications Center (PEAC), where he managed EPRI-sponsored power electronics research projects. From 1993, he worked with the Oak Ridge National Laboratory as the Power Electronics Lead Scientist, where he initiated a high power electronics program and developed several novel high power converters including multilevel converters and softswitching inverters. His work brought him several distinctive awards including a Technical Achievement Award in Lockheed Martin Award Night, three IEEE IAS Conference Paper Awards, Best Paper Awards from IECON-97, IPEC05, and PCC-07. In 1996, he joined Virginia Polytechnic Institute and State University. His student teams won three awards from future energy challenge competitions and the first place award from TI Enginous Prize Analog Design Competition. He is currently a professor and the Director of the Future Energy Electronics Center. His main research areas are in high efficiency power electronics conversions for high power and energy applications. He has published more than 240 technical papers and 2 books and received 20 U.S. patents. Dr. Lai chaired the 2000 IEEE Workshop on Computers in Power Electronics (COMPEL 2000), 2001 IEEE/DOE Future Energy Challenge, and 2005 IEEE Applied Power Electronics Conference and Exposition (APEC 2005). 